1

2

3

4

5

6

7

8

10

11

12

13

14

15

16

17

18

19

20

21

22

23

24

25

26

27

28

29

30

31

32

33

34

35

36

37

38

39

40

41

42

43

44

45

46

47

48

49

50

51

52

53

54

55

56

57

58

59

60

\section{Natural carriers for application in tuberculosis treatment}

Hugo Costa, Ana Grenha

CBME - Centre for Molecular and Structural Biomedicine / IBB - Institute for Biotechnology and Bioengineering, Faculty of Sciences and Technology, University of Algarve, Campus de Gambelas, 8005-139 Faro, Portugal

*Corresponding author:

University of Algarve

CBME/IBB, Faculty of Sciences and Technology

Campus de Gambelas

8005-139 Faro, Portugal

Tel.: +351 $289800100-$ Ext. 7441

Fax: +351289818419

E-mail address: amgrenha@,ualg.pt

Keywords: controlled release, drug delivery, microencapsulation, microparticles, nanoparticles 


\begin{abstract}
Tuberculosis remains the leading cause of preventable deaths worldwide and unsuccessful therapy is mainly due to non-compliance with very prolonged treatments, often associated with severe side-effects. Overcoming this problem demands the introduction of drug carriers releasing the antimicrobial agents in a targeted and sustained manner, allowing reduction in frequency and dosing numbers. Nano and microparticles have taken the forefront of this approach, providing the means for the desired improvement of therapeutic schedules. Natural polymers are strong candidates as matrix forming materials, usually exhibiting biocompatibility, biodegradability, low cost and some technological advantages as compared with synthetic counterparts. In this review, natural particulate carriers developed for tuberculosis therapy are presented, mainly focusing on the use of polysaccharides and lipids. Their effectiveness is discussed taking into account their composition. Finally, considerations on the general potential of natural materials for this application, as well as key factors still to be addressed, are discussed.
\end{abstract}




\section{Introduction}

Tuberculosis is a highly contagious bacterial infection caused by Mycobacterium tuberculosis and, although its first reliable therapeutic approach came out in 1944, with the discovery of streptomycin, the disease remains the leading cause of preventable deaths worldwide (Ranjita et al., 2011). 86\% of the cases are reported to occur both in Asia and Africa, especially in developing countries that lack adequate health conditions and face difficult medical access. Moreover, some disease conditions are known to increase the susceptibility of tuberculosis infection, such as the infection with human immunodeficiency virus (HIV), diabetes and chronic lung disease (Ranjita et al., 2011, Doherty and Andersen, 2005). In this manner, the disease is a major burden in developing countries, but it also remains present in many developed countries. Humans are the primary host of Mycobacterium tuberculosis, which is disseminated via inhalation of bacteria-containing droplets. For this reason, the disease is known to mainly affect the lungs (Blasi et al., 2009). However, it can also disseminate to extrapulmonary regions, affecting any other place in the organism, mainly the central nervous and the circulatory systems (Ranjita et al., 2011, Sosnik et al., 2010). When the infectious droplet nuclei are inhaled, mycobacteria reach the alveoli and accumulate inside alveolar macrophages. Once inside macrophages, a cascade of events is started. As a result, the infection can be contained or the bacillus can keep multiplying, leading to the progression to active disease (Blasi et al., 2009, du Toit et al., 2006). This difference in responses mainly depends on whether the infected individual has the ability to start an adequate immunological response. Further details on the pathogenesis of tuberculosis might be found in (Russell, 2007, Hunter, 2011). When capturing bacteria, as occurs for any other particulate matter, macrophages become activated. This activation refers to a state of enhanced cellular metabolism, mobility, lysosomal enzyme 
activity and cytocidal capacity (Lewis and McGee, 1992, Ahsan et al., 2002). Activation mainly occurs in response to activation signals such as interferon- $\alpha$, along with the exposure to a microbial product like lipopolysaccharide (Mosser, 2003). Generally, activated macrophages are not more phagocytic than others, but they possess a markedly enhanced ability to eliminate intracellular microorganisms (Mosser, 2003, Lewis and McGee, 1992). Yet, a recent work reports the increase of phagocytic activity by mycobacteria-infected macrophages as compared with non-infected cells (Hirota et al., 2008). In the particular case of tuberculosis, starting this activation process initiates a pro-inflammatory cascade that includes the recruitment of several other types of cells to the infection site. This contributes to the formation of the granuloma, which consists of a core of infected macrophages surrounded by mononuclear phagocytes, capillaries and a peripheral layer of lymphocytes (Blasi et al., 2009, Misra et al., 2011). The formation of the granuloma endows the bacteria with the ability to avoid cell mediated immune response (Armstead and Li, 2011).

Current tuberculosis therapy is complex and involves the so-called 'directly observed treatment, short-course' (DOTS), which uses a multidrug approach to prevent drug resistance. The treatment demands the oral administration of four different antibiotics for a period of six months and is many times associated with severe side effects, such as hepatotoxicity, nephrotoxicity and ototoxicity (Sosnik et al., 2010, Smola et al., 2008). This conjugation of a prolonged treatment and the recurrent appearance of side effects, results frequently in very low patient compliance, leading to a relapse of symptoms and increased prevalence of multidrug-resistant strains (Pandey and Khuller, 2005a). Having this problem identified, industrial and academic researchers are directing efforts to the development of alternatives that simultaneously increase patient compliance and provide therapeutic efficacy. On one side, research is being directed towards the 
development of new and potent drugs that overcome resistance mechanisms developed by bacteria, although these will take years to reach the market. On the other side, the use of alternative routes of administration and new formulations of anti-tubercular drugs that provide sustained release is being explored.

This latter approach is the focus of the present review. Herein, several alternatives proposed in the literature for the administration of anti-tubercular drugs are presented, considering not only unconventional administration routes, but also the use of specifically designed drug delivery carriers. These approaches envisage the improvement of patient compliance, with consequent enhanced therapeutic results, not only because they possibly reduce doses and dosing frequency but also because this will inevitably lead to reduced incidence of side effects. A significant part of the works available in the field propose drug carriers based on synthetic polymers, namely polylactic acid (PLA) and polylactic-co-glycolic acid (PLGA), which are known for their biocompatibility. However, these synthetic carriers present some critical limitations, mainly related with low drug encapsulation, the elimination of residual organic solvents and generally associated high costs. These problems potentiate the choice for natural materials, which have the great advantage of being more prone to biodegradability and biocompatibility, and are readily available at low and convenient prices (Beneke et al., 2009). This review will be dedicated to multiparticulate drug delivery systems whose composition is based on natural materials, emphasising the application of polysaccharides and lipids in the production of micro and nanocarriers. Liposomal formulations are also relevant in this field, but a very recent and complete review on the subject is available (Pinheiro et al., 2011) and, therefore, the application of these systems will not be included. The effectiveness of formulations will be addressed on the basis of their specific composition and intrinsic properties. In addition, 
a general consideration on the potential of carriers formed by natural materials for a particular application in the design of anti-tubercular drug delivery systems will be drawn by the authors.

\section{Natural drug carriers designed for tuberculosis treatment}

So far, tuberculosis therapies have mainly explored conventional routes of administration, such as oral and intra-muscular, as well as the most usual pharmaceutical dosage forms, which include tablets, capsules and injectable solutions (Blasi et al., 2009). The oral route, currently the most used in anti-tubercular therapy, although very convenient for the patients, presents limitations related with premature drug degradation and difficulty to allow the drug to reach relevant tissues, such as the lungs. Besides, many antibiotics that are highly active in vitro are often inactive against intracellular bacteria, due to their poor penetration into the cells (Saraogi et al., 2011). Therefore, it has been recognised that the necessary decrease of dosing frequency, as well as that of side-effects, cannot be accomplished by conventional therapeutic approaches, instead demanding the use of drug delivery systems that provide controlled release and concentrate the drug at the infection site. For instance, as $80 \%$ of tuberculosis cases affect the lungs, which is the site of entrance of the bacteria, the direct targeting of alveolar macrophages, where bacteria are hosted, would be extremely useful. This effect could be achieved through inhalable therapies that provide high local concentration of drug and rapid onset of killing action (Mitchison and Fourie, 2010). In this manner, the encapsulation of drugs into micron- or nanosized carriers might be the adequate strategy to both decrease toxicity and provide a controlled release (Blasi et al., 2009, Sosnik et al., 2010). As an additional advantage, it is known that particulate matter has increased macrophage capture as compared with solutes, owing to 
phagocytosis (Ahsan et al., 2002, Geiser, 2010, Misra et al., 2011). Moreover, as it was previously emphasised, there is an indication of increased phagocytic activity evidenced by mycobacterium-infected macrophages (Hirota et al., 2008). Both nanoparticles and microparticles have, thus, been proposed to this end, either being composed of natural or synthetic materials. In this context, the greatest advantages achieved by natural polymeric particles, as compared to synthetic counterparts, are the highest encapsulation efficiency and the lower drug-to-polymer ratio, allowing improved loadings with smaller polymer quantities (Blasi et al., 2009, Pandey and Ahmad, 2011). Natural polymers evidence some specific advantages, including their general biocompatibility, low cost and hydrophilicity (Liu et al., 2008, Anwunobi and Emeje, 2011, Mizrahy and Peer, 2012). The latter is of particular importance in designing drug delivery systems, as it permits avoiding the use of organic solvents. Table 1 presents the advantages and limitations of natural polymers as matrix forming materials. In the next sections, an overview of the potentialities of those carriers that are based on natural materials, which include several polysaccharides and lipids, is provided. Tables 2 and $\mathbf{3}$ present a summary of the most important findings of the works described along this review.

Table 3 specifically addresses the results obtained in in vivo studies performed in animal models of tuberculosis, providing data on the therapeutic efficacy of the developed systems.

\section{Polymeric microparticles}

A very short list of natural materials was used so far to produce microparticles aimed at delivering anti-tubercular drugs. Alginate, chitosan, hyaluronic acid, carboxymethyl cellulose and gelatin are those reported in the literature, addressing both oral and pulmonary administration. The chemical structures of these materials are depicted in 
Figure 1. Alginate is a polysaccharide composed of $\beta$-D-mannuronic and $\alpha$-L-guluronic acid that is usually extracted from brown seaweed. Chitosan is another polysaccharide, is composed of D-glucosamine and $N$-acetyl-glucosamine units, and is obtained by the deacetylation of chitin, which is extracted from arthropods, mainly crab shells. Hyaluronic acid is a glycosaminoglycan composed of units of $\mathrm{N}$-acetyl-glucosamine and glucuronic acid. Carboxymethylcellulose is a cellulose derivative in which the glucopyranose backbone presents carboxymethyl groups attached to some of its hydroxyl moieties. The application of these polymers in drug delivery is widely reported, as they evidence biocompatibility, biodegradability and, in some cases, mucoadhesive properties, which are more pronounced in chitosan (Beneke et al., 2009, Chiellini et al., 2008, Sudhakar et al., 2006). Gelatin is a protein derived from collagen, with reported biocompatibility and biodegradability (Chiellini et al., 2008, Malafaya et al., 2007). Albumin microspheres are also described (Yeboah and D'souza, 2009), but their application focuses on the oral administration of vaccines, therefore being out of the scope of this review.

To the best of our knowledge, the first report on the production of natural microparticles for the delivery of anti-tubercular drugs appeared in 2003, using alginate as matrixforming material and focusing on oral administration. The microparticles (100 $\mu \mathrm{m})$ were prepared by ionic gelation with $\mathrm{Ca}^{2+}$ and encapsulated isoniazid, rifampicin and pyrazinamide in combination. Upon oral administration of a single dose to guinea pigs, a sustained release of the encapsulated drugs was observed for 3-5 days, while the free drugs were only present in plasma until $24 \mathrm{~h}$, approximately. Moreover, as depicted in Figure 2, the administration of microcapsule formulations provided the detection of drugs in several organs (lungs, liver, spleen, intestine) up to 9 days, while the oral delivery of free drugs only resulted in detectable levels up to $48 \mathrm{~h}$ in liver and spleen. 
Importantly, the microencapsulation approach permitted a 9-fold increase in bioavailability as compared with free drugs. A proof-of-concept study was performed using a tuberculosis animal model, demonstrating the elimination of bacilli in lungs and spleen after eight weeks of therapy comprising of a weekly oral administration. The same treatment duration was used for free drugs and similar results were observed, but a daily administration was required (Ain et al., 2003). The same group altered this formulation by including chitosan, in order to further improve bioavailability by retarding particle erosion and, thus, enabling the reduction of dosing frequency. The administration of a single oral dose of these new microparticles $(70 \mu \mathrm{m})$ resulted in detectable plasma drug levels for 7 days (Figure 3), increasing the bioavailability in comparison with the formulation without chitosan (above). As compared with the results provided by simple alginate microspheres, which led to a 9-fold enhancement of bioavailability, these alginate-chitosan microspheres reached up to 19-fold bioavailability increase. Consequently, as compared with free drugs, a 15- and 13-fold increase in half-life and mean residence time, were observed. In addition, an interesting study provided a comparison between the in vivo administration of therapeutic and halftherapeutic doses of the referred drugs to an animal model of the disease (guinea pigs). Oral administration of free drugs demanded 46 doses to eliminate the bacilli, while the same effect was observed with only 5 doses of microencapsulated drugs at therapeutic concentration or 7 doses at half-therapeutic concentration, administered every 10 days (Pandey and Khuller, 2004). The alginate and alginate-chitosan microspheres, were observed to provide a sustained drug release in intestinal medium (up to 20 days), which is in the basis of the prolonged detection of drugs in plasma for several days. For the formulation containing only alginate, this observation is rather unexpected, because alginate is a loose hydrogel network that degrades at the neutral $\mathrm{pH}$ characteristic of the 
intestinal area (George and Abraham, 2006). As the encapsulated drugs have low molecular weight, and considering that the microspheres were not cross-linked, the observed release profile is even more surprising, but it probably relates to the proper alginate composition. It is known that drug release from alginate matrices is strongly affected by the matrix structure (Murata et al., 2007, d'Ayala et al., 2008). In this context, alginates with high guluronic content provide stiffer gels that maintain their integrity for long periods of time and exhibit restrict solute transport (d'Ayala et al., 2008). Together with the mucoadhesive properties of the polymer, this has been the basis for the observation of the long lasting plasma drug levels. Concerning the formulation containing chitosan, the presence of this polycation was proposed to control microspheres porosity, enhancing the sustained release effect. The increased bioavailability observed upon incorporation of chitosan might be justified by the strong mucoadhesive properties of the polymer, as well as by its reported ability to transiently open tight junctions (Lehr et al., 1992, Braz et al., 2011). The demonstration of the possibility to control the delivery of drugs, achieving sustained plasma levels for several days is in fact a great step forward towards therapeutic advancements that might improve therapeutic efficiency. In this sense, higher bioavailability allows lower frequency of administration and, in the case of the formulation containing chitosan, even lower dose.

There is also a work describing the use of gelatin/carboxymethylcellulose to prepare microparticles aimed at delivering isoniazid. Microparticles were produced by emulsification in presence of Tween $80^{\circledR}$ and, although the authors do not refer to it directly, microparticle development was aimed at oral administration, because the smallest size observed for the systems is around 150-200 $\mu \mathrm{m}$. Glutaraldehyde was used as cross-linker, evidencing the ability to modulate water uptake and drug release. Two 
different degrees of cross-linking were tested, with the highest $(17.5 \mathrm{mmol}$ glutaraldehyde/g of polymer) resulting in $70 \%$ drug release in $48 \mathrm{~h}$, in contrast with the lowest $(4.375 \mathrm{mmol} / \mathrm{g}$ of polymer), which provided $90 \%$ of release at $24 \mathrm{~h}$ (Devi and Maji, 2009). Unfortunately, no data on the therapeutic efficacy of this system are available and, without a doubt, one of the major drawbacks of the developed system is the need to involve glutaraldehyde as cross-linker.

As stated in the introduction, lung tuberculosis is the main manifestation of the disease and, therefore, the direct administration of anti-tubercular drugs to the lung, where the macrophages hosting the mycobacterium reside, appears as a logical and potentially promising approach. To address this possibility, ofloxacin-loaded hyaluronic acid microparticles $(2-5 \mu \mathrm{m})$ were prepared by spray-drying and administered intratracheally to rats. The systemic bioavailability provided by microencapsulated ofloxacin, as compared to control intravenous and oral administration of drug solution in the same dose, was less than $50 \%$, indicating a lower efficiency in the treatment of extrapulmonary tuberculosis. However, the concentration of the drug in the lung was 10times higher following direct delivery to the lung, demonstrating the great potential of the formulation in the therapy of lung tuberculosis. This effect was also much more pronounced for ofloxacin-loaded hyaluronic acid microparticles as compared to the unformulated powder of the drug (Hwang et al., 2008), evidencing a positive effect of the hyaluronic acid that is justified by its mucoadhesive character (Grabovac et al., 2005). Encapsulation in presence of the polymer was also reported to enhance the in vitro uptake of ofloxacin by macrophages (cell line RAW 264.7), as compared to control ofloxacin microparticles spray-dried in the absence of polymer (Hwang et al., 2008). Apart from the recognition of hyaluronan evidenced by CD44 receptors of macrophages, as the authors mentioned, this effect might be additionally attributed to a 
specific recognition by lectin-type receptors that are also present, which recognise the $\mathrm{N}$-acetylglucosamine residues (Taylor et al., 2005) comprising the structure of hyaluronic acid.

Among all the described formulations of polymeric microparticles, only those composed by alginate were tested in animal models of the disease. Alginate-based microparticles demonstrated, thus, to be therapeutically effective when administered through the oral route. However, the formulation designed for direct lung delivery of ofloxacin might have potential in the treatment of lung tuberculosis, as demonstrated by the high lung drug levels that were reported. Nevertheless, with the exception of the works with alginate, the major flaw that is identified in formulation design relies in the use of a single drug. As pointed out in the introduction, the current approach of tuberculosis therapy always includes multiple drug administration, as single therapy is absolutely contra-indicated due to resistance issues.

\section{Polyalcohol microparticles}

Among the polyalcohols, only mannitol has been reported for an application in tuberculosis therapy. Mannitol (Figure 1) is a sugar alcohol that has been frequently used in particle formulation as matrix-forming material. In our group it was used several times as matrix material in microparticles designed for lung administration, as it provides good flow properties (Grenha et al., 2005, Grenha et al., 2008, Al-Qadi et al., 2011).

In the only work reporting its application, mannitol was used as matrix-forming material for the production of microparticles $(3-4 \mu \mathrm{m})$ aimed at direct lung administration and rifampicin was used as anti-tubercular drug. The aerosolisation pattern of rifampicin was improved when microencapsulated with mannitol. However, intratracheal 
administration in vivo to rats demonstrated that drug elimination is very rapid (only $4 \%$ of the drug remained in the lung after $1 \mathrm{~h}$ ) (Mizoe et al., 2008), indicating an efficacy below the desired level to attain a therapeutic effect. This result was rather predictable, as mannitol is very soluble in aqueous medium and even in the presence of a small quantity of medium, as that existing in the alveolar zone, rapid dissolution of the microparticle matrix is expected, releasing the drug and enabling its rapid elimination. In this sense, as previously commented regarding some of the described works, the application of a mucoadhesive polymer as component of the microparticle matrix would be adequate to provide a more prolonged retention.

\section{Polymeric nanoparticles}

Works dedicated to the design of nanoparticulate carriers in the ambit of tuberculosis therapy almost double those of microparticles, as easily observed by consulting a database like ISI Web of Knowledge. This marked difference becomes even more relevant if considering that microencapsulation techniques have been available for a much longer time, as compared with technologies for nanoparticle production. The major reason for this difference is the fact that nanotechnologies have revealed a huge potential owing to their small dimensions, including the capacity for cell internalisation and to permeate epithelial barriers, as well as to improve encapsulation efficiency, compared with microparticles (Ranjita et al., 2011, Pandey and Ahmad, 2011, Ahmad et al., 2006a). The mentioned difference in the number of works between nano and microparticles is not observed when natural materials are used, instead being approximately similar. Nevertheless, the list of natural polymers used in the formulation of nanoparticles proposed as vehicles in tuberculosis therapy is even narrower as 
compared to that of microparticles, comprising only alginate, chitosan, gelatin and dextran sulfate (chemical structures of materials depicted in Figure 1).

Curiously, the first report on natural nanoparticle carriers addressing tuberculosis therapy was devoted to inhalation. Although the authors refer to the system merely as alginate nanoparticles, which were formed by gelification with calcium ions, these were subsequently coated with chitosan by electrostatic interaction. Isoniazid, pyrazinamide and rifampicin were encapsulated in the nanoparticles $(235 \mathrm{~nm})$ at a drug/polymer ratio of 7.5/1 and administered by nebulisation to guinea pigs infected with Mycobacterium tuberculosis. Aerodynamic studies revealed that $80 \%$ of the nebulised particles were in the respirable range, ensuring alveolar deposition. Very interesting results were obtained in vivo (Table 4), so that only 3 doses of nanoparticles in a total of 45 days resulted in undetectable mycobacteria in lung and spleen homogenates; the same observation registered upon 45 daily doses of the free drugs by the oral route. This tremendous reduction in dosing frequency was possible owing to the detection of drug levels in plasma for up to 14 days after nanoparticle administration, as compared to only 1 day upon administration of free drugs. Additionally, enhanced tissue bioavailability was also reported in several organs (lungs, liver spleen), as encapsulated drugs provided detectable levels up to 15 days (Ahmad et al., 2005b). In spite of the promising results, a broad characterisation of the nanoparticles is missing (morphological studies, in vitro release, etc.), limiting the discussion of results. Unfortunately, this research line was not continued until now, as no more recent data are available.

In turn, a decision was apparently made to proceed with the application of the formulation in oral delivery. One of the reasons pointed as the basis of this decision is the fact that nanoparticle uptake by intestinal cells has been reported several times, either by the M-cells located in the Peyer's patches (Borges et al., 2006, Pinto Reis et 
al., 2006) or by the enterocytes, benefiting from transcellular and paracellular transport (Cai et al., 2010, Pinto Reis et al., 2006). A first study revealed that, after oral delivery to mice of alginate nanoparticles containing the three drugs mentioned above plus etambutol, plasma drug levels were detected during 7-13 days. As happened before upon inhalation, tissue drug levels were detected up to 15 days. In contrast, the administration of free drugs led to plasma and tissue elimination within $24 \mathrm{~h}$ (Ahmad et al., 2006c). A second work provided the in vivo proof-of-concept of the formulation for oral administration, demonstrating that 3 oral doses of encapsulated drugs administered fortnightly to Mycobacterium tuberculosis-infected mice, resulted in complete bacterial clearance, as was observed upon administration of 45 daily doses of free drugs (Ahmad et al., 2006a). A later approach has associated econazole to the four anti-tubercular drugs used before (Ahmad et al., 2007), benefiting from its demonstrated potent antitubercular activity and synergism with some anti-tubercular drugs (Ahmad et al., 2005a). In fact, econazole has proven to have similar chemotherapeutic potential as compared with rifampicin (Ahmad et al., 2006d, Ahmad et al., 2006b). In the referred work, it was observed that Mycobacterium tuberculosis-infected mice had undetectable bacterial levels after 30 days of treatment with alginate nanoparticles encapsulating econazole and three of the usual anti-tubercular drugs (fortnight administration, except for econazole that demands a weekly administration). The same result was obtained with the daily administration of the free drugs (twice daily for econazole). Econazole was demonstrated to substitute rifampicin or isoniazid without compromising the final therapeutic outcome (Ahmad et al., 2007).

Three other works reported the use of natural nanoparticle carriers for anti-tubercular drugs, both sharing the major limitation of encapsulating and delivering a single drug. In one case, chitosan-coated complexes of streptomycin and dextran sulfate (500 nm) 
are administered daily through the oral route to Mycobacterium tuberculosis-infected mice for a period of 3 weeks. Bacterial levels decreased by about $15 \%$ as compared to untreated animals and a similar result was obtained upon the same schedule of subcutaneous administration of streptomycin solution ( $\mathrm{Lu}$ et al., 2009). The efficacy of the formulation is substantially lower than that observed for alginate formulations presented before and, unfortunately, controls such as the oral administration of free drug, for instance, were not reported. Gelatin nanocarriers prepared by desolvation (264 $\mathrm{nm})$ were also proposed, this time for the intravenous administration of rifampicin to mice. Although the administration of nanoparticles was more efficacious than free drugs, 10 doses administered every 3 days only reduced bacterial levels in lungs and spleen by about 50\%, without completely eliminating the bacteria (Saraogi et al., 2010). More recently, these nanoparticles were conjugated with mannose and loaded with isoniazid, and then administered intravenously to mice, as a means of providing a direct targeting of alveolar macrophages (Saraogi et al., 2011), taking benefit from the presence of mannose receptors in macrophages surface (Ahsan et al., 2002, Geiser, 2010). Lung targeting was achieved and a 3-fold higher reduction of mycobacteria was observed upon the administration of mannosylated nanoparticles, as compared to free drug. Although to a lower extent, non-mannolsylated nanoparticles also improved bacterial elimination as compared to free drugs, registering a 2-fold higher reduction. This is a clear indication of a more effective internalization by macrophages of the nanoparticles bearing surface residues of mannose, as also demonstrated in an in vitro assay with a macrophage cell line (J774) (Saraogi et al., 2011).

As observed for the microparticulate systems, alginate-based formulations were the most successful in eliminating bacteria. Interestingly, the presented set of works demonstrated that 3 doses of drug loaded chitosan-coated alginate nanoparticles, either 
administered orally or by inhalation with intervals of 15 days, are effective in eliminating mycobacteria from the affected tissues. Importantly, therapy duration can be further reduced by substituting rifampicin or isoniazid by econazole, providing bacterial elimination with only 2 fortnight doses.

\section{Solid lipid nanoparticles}

Solid lipid nanoparticles differ from polymeric nanoparticles in their composition, which is based on lipids. This lipidic content endows the nanoparticles with biocompatibility and biodegradability. In addition, as compared to liposomes, their production is easily scalable and they offer increased drug protection, as there is limited access of water to the inner lipidic core (Martins et al., 2007, Attama, 2011). These nanoparticles were previously used successfully to improve the bioavailability of distinct drugs, such as idarubicin (Zara et al., 2002), tobramycin (Cavalli et al., 2003) and insulin (Fonte et al., 2012), amongst others.

In the context of anti-tubercular therapy, solid lipid nanoparticles based on stearic acid (Figure 1) and prepared by emulsion solvent diffusion were loaded with rifampicin, isoniazid and pyrazinamide, and administered by both the oral (Pandey et al., 2005) and the pulmonary route (Pandey and Khuller, 2005b) to Mycobacterium tuberculosisinfected mice and guinea pigs, respectively. After oral administration, therapeutic drug levels were detected in plasma for 8 days and in tissues (lung, spleen, liver) for 10 days. Five oral doses administered each 10 days led to undetectable levels of bacteria, whereas equivalent therapeutic result was obtained after 46 daily doses of free drugs (Pandey et al., 2005). Inhalable therapy (nebulisation) led to shorter availability times (5 days in plasma and 7 days in tissues) but was also therapeutically effective, providing elimination of the bacilli after 7 weekly doses of the formulation (Pandey and Khuller, 
2005b). Although the results seem interesting, a thorough characterisation of the nanoparticles is not available. Actually, important parameters such as the morphological and physicochemical properties, namely size and zeta potential, which are known to strongly affect the performance of nanoparticulate carriers, are missing, compromising the interpretation of results. As applied before to polymeric nanoparticles, mannosylation was also used as a strategy to improve macrophage targeting of solid lipid nanoparticles. Mannosylated solid lipid nanoparticles loaded with rifabutin (390 $\mathrm{nm}$ ) revealed a 6-times increase in particle uptake (in vitro, macrophage cell line J774) and more prolonged drug retention in plasma ( $96 \mathrm{~h}$ as compared to $72 \mathrm{~h}$ provided by non-mannosylated particles and $48 \mathrm{~h}$ of free drug) and tissues after intravenous administration of one dose (Nimje et al., 2009).

Solid lipid nanoparticles have recently emerged as promising technology, particularly for the delivery of hydrophobic drugs, as with for many anti-tubercular drugs. Owing to the generally regarded as safe status of lipids and the previously mentioned advantages in comparison with liposomes, there are some indications on their effectiveness as drug carriers. Nevertheless, in the particular case of anti-tubercular therapy, an additional number of studies would be needed to state their usefulness.

\section{Conclusions and perspectives}

As stated through the review, a great number of works devoted to tuberculosis has been focusing on the design of new therapeutic alternatives for this pertinent disease, particularly addressing the limitation of low patient compliance caused by prolonged therapies and associated side-effects. The defined strategy focuses on encapsulation procedures that modify drug pharmacokinetics and, in some cases, further approach the use of unconventional routes of administration. Encapsulation automatically provides 
the drugs with prolonged half-life, because drug delivery systems take longer to be eliminated as compared with free drug molecules, especially if the used polymers are hydrophilic (Pandey and Ahmad, 2011). In addition, with the selection of an adequate carrier composition, sustained drug release can be attained, leading to a reduction in dosing frequency and to decreased side-effects. In fact, the outstanding effect of achieving controlled release is the tremendous improvement in therapeutic schedules, replacing the usual 46 daily oral doses by a much reduced number of administrations. As demonstrated in some of the described studies, a total of 2 or 3 administrations spaced by two weeks, might be enough for bacterial elimination, which would represent an enormous improvement on therapeutic frequency. In some cases, however, the works propose intravenous administration. Considering that this encompasses painful procedures, higher infection risks and requires skilled personal, it is not the ideal route on admitting a marketing approach. Additionally, taking into account that developing countries would be the main beneficiary of these new therapeutic lines, parenteral administration should not be pondered, as it raises the problem of demanding sterilised material that in most cases is not possible to provide.

The oral and pulmonary routes were proposed in the majority of works, addressing this limitation, although inhalation is focused in a lower number of reports, comparatively. Bearing in mind the previously mentioned prevalence of lung tuberculosis, systemic absorption of drugs released from orally administered drug delivery systems is demanded and their delivery to the lung expected. In parallel, although theoretically drug delivery systems could be taken up by intestinal M-cells and delivered to the lungs through the lymphatic circulation (Florence, 1997, Hans and Lowman, 2002), several works have demonstrated the absence of efficacy of this strategy (Azarmi et al., 2008). In the development of tuberculosis therapy it is important to consider that 
Mycobacterium tuberculosis is an intracellular parasite, especially in the chronic phase of the disease. Therefore, whatever the route of administration, once in the lung, intracellular internalisation of drugs is necessary (Barrow, 2004).

In this context, delivering encapsulated anti-tubercular drugs directly to the lung might be a very useful approach and has demonstrated in several works to enhance local (lung tissue) bioavailability, serving as targeted anti-tubercular drug delivery. This approach optimises drug therapeutic index by increasing drug concentration ratio of diseased tissue to normal tissue (Saraogi et al., 2010), improving chemotherapeutic efficacy and reducing dose frequency. In addition, by avoiding high plasma drug levels, usual toxic effects are dramatically reduced. Nevertheless, considering the intracellular localisation of the bacteria, an increase in tissue levels is only relevant if leading to an intracellular accumulation of the drugs and, therefore, care must be taken on the interpretation of results. An additional advantage of inhaled carrier-based therapies relies on the activation of infected macrophages as a consequence of the uptake of particulates, resulting in improved bactericidal activity (Mosser, 2003, Lewis and McGee, 1992). Notwithstanding the promising inhalation approach, several important limitations have been noted, including limited access to poorly aerated areas of the lung, resistance derived from intracellular drug concentration and immunopathological reactions derived from macrophage activation (Yadav et al., 2011).

Considering that the lung is the port of entrance of tuberculosis infecting agent and taking into account the mentioned prevalence of lung tuberculosis, the absence of a commercial inhalable therapy can be surprising. It seems logical to assume that formulating inhalable delivery systems is much more challenging than designing oral systems, but that is possibly only the easiest justification. Indeed, lung delivery is much less studied and its impact on general health is not really established, raising a strong 
concern that both does not stimulates researchers and makes regulatory agencies to be very cautious regarding the approval of these therapies.

As previously mentioned, no matter what the route of delivery, using drug delivery systems is a key factor in meeting the mandatory requirements of decreasing dosing frequency and side-effects. Nano and microparticles have taken the forefront of this challenge and polyesters such as PLA and PLGA lead the list of materials described to compose their matrices. The reason for this fact is easily attributed to their reported biocompatibility and to the variable methods described to produce the carriers. However, important limitations of these synthetic materials have also been identified, such as low encapsulation efficiencies and difficulties to eliminate organic solvents involved in carrier production methods. The interest is now turning to the application of natural materials, which are produced with much more rapid and mild methods, have a lower cost and evidence similar biocompatibility profile. In addition, if adequately selected, they can permit a direct targeting of macrophages, by specific recognition mediated by alveolar surface receptors. In this context, macrophages express various surface receptors, including Fc, mannosyl, lectin, and galactosyl (Ahsan et al., 2002, Geiser, 2010), and this strategy would present the outstanding advantage of delivering therapeutically effective drug concentrations to the primary site of infection (Smola et al., 2008).

In comparison with microparticles, nanoparticles usually provide higher drug loading (Ahmad et al., 2011). However, the selection of one system or the other might be dependent on the designated route of administration. When oral delivery is intended, nanoparticles might be able to provide not only a more effective controlled release of drugs, but also the possibility of systemic transport of the carriers. Pulmonary delivery is also possible for both nanoparticles and microparticles, but while micron-sized 
carriers can be tuned to display the adequate aerodynamic properties to achieve the alveolar zone, nanocarriers require additional processing such as subsequent microencapsulation to provide a dry powder formulation or the use of nebulisation to afford the adequate dimensions. On the contrary, if macrophage targeting is aimed through inhalation, it was suggested that microparticles of 1-3 $\mu \mathrm{m}$ have maximal uptake (Ahsan et al., 2002, Misra et al., 2011), while that of submicron particles was rather sporadic and unintentional (Geiser, 2010). In this manner, if by one side nanomedicines seem to be the most adequate and efficacious solutions for improving TB therapy in oral delivery, microparticles are possibly the most promising for the treatment of lung tuberculosis by inhalation. In the latter approach, carriers displaying surface molecules specifically recognised by macrophage surface receptors (i.e. mannose) have improved targeting efficacy. Organic synthesis is usually applied to conjugate the targeting ligands to the polymers, but the same purpose might be achieved with the selection of proper natural materials. In this context, it was demonstrated in a previous work that chitosan microparticles were captured by alveolar macrophages after intra-tracheal administration to rats (Al-Qadi et al., 2012). Although the microparticle-cell interaction was not specifically studied, maybe recognition of $\mathrm{N}$-acetylglucosamine units took place, in addition to the natural tendency of macrophages for particle internalisation.

In the whole approach of developing alternative strategies that permit an increase of patient compliance, some important details are, however, still to be improved. In many cases, works report single drug therapy, which is not adequate because of drug resistance. Instead, multidrug therapeutic approaches are mandatory for research aiming at real implementation. On the other side, it is very important to realise that even the more realistic assays performed in infected animals, do not necessarily describe the outcome to be obtained in humans. As a matter of fact, a much important parameter 
such as macrophage turnover time is absolutely variable within species, being reported as 21-28 days in mouse and 81 days in humans (Geiser, 2010). Moreover, it is also important to consider the general concern lying around the administration of particulate matter to the lung (Misra et al., 2011), as little information is available on the subject reporting human application.

It is a fact that, so far, only a limited number of formulations undertook in vivo testing regarding therapeutic effectiveness. Nevertheless, with the important outcomes described through this review, it seems realistic to suppose that future anti-tubercular therapy will follow the basis of the proposed strategies, using carrier-based approaches. Natural polymers seem to have a word in this context, but more studies are obviously needed to explore the whole potential of these materials, namely in what concerns the use of a wider variety of polymers.

\section{Declaration of interest}

This work was supported by national Portuguese funding through FCT - Fundação para a Ciência e a Tecnologia, project PEst-OE/EQB/LA0023/2011 and PTDC/SAUFCF/100291/2008.

\section{References}

AHMAD, Z., MAQBOOL, M. \& RAJA, A. 2011. Nanomedicine for tuberculosis: Insights from animal models. International Journal of Nano Dimension, 2, 67-84.

AHMAD, Z., PANDEY, R., SHARMA, S. \& KHULLER, G. K. 2006a. Alginate nanoparticles as antituberculosis drug carriers: formulation development, pharmacokinetics and therapeutic potential. Indian Journal of Chest Diseases and Allied Sciences, 48, 171176.

AHMAD, Z., PANDEY, R., SHARMA, S. \& KHULLER, G. K. 2006b. Azole antifungals as novel chemotherapeutic agents against murine tuberculosis. FEMS Microbiology Letters, 261, 181-186. 
AHMAD, Z., PANDEY, R., SHARMA, S. \& KHULLER, G. K. 2006c. Pharmacokinetic and pharmacodynamic behaviour of antitubercular drugs encapsulated in alginate nanoparticles at two doses. International Journal of Antimicrobial Agents, 27, 409-416.

AHMAD, Z., SHARMA, S. \& KHULLER, G. K. 2005a. In vitro and ex vivo antimycobacterial potential of azole drugs against Mycobacterium tuberculosis H37Rv. FEMS Microbiology Letters, 251, 19-22.

AHMAD, Z., SHARMA, S. \& KHULLER, G. K. 2005b. Inhalable alginate nanoparticles as antitubercular drug carriers against experimental tuberculosis. International Journal of Antimicrobial Agents, 26, 298-303.

AHMAD, Z., SHARMA, S. \& KHULLER, G. K. 2006d. The potential of azole antifungals against latent/persistent tuberculosis. FEMS Microbiology Letters, 258, 200-203.

AHMAD, Z., SHARMA, S. \& KHULLER, G. K. 2007. Chemotherapeutic evaluation of alginate nanoparticle-encapsulated azole antifungal and antitubercular drugs against murine tuberculosis. Nanomedicine: Nanotechnology, Biology and Medicine, 3, 239-243.

AHSAN, F., RIVAS, I. P., KHAN, M. A. \& TORRES SUÁREZ, A. I. 2002. Targeting to macrophages: role of physicochemical properties of particulate carriers-liposomes and microspheres-on the phagocytosis by macrophages. Journal of Controlled Release, 79, 29-40.

AIN, Q., SHARMA, S., KHULLER, G. K. \& GARG, S. 2003. Alginate-based oral drug delivery system for tuberculosis: pharmacokinetics and therapeutic effects. Journal of Antimicrobial Chemotherapy, 51, 931-938.

AL-QADI, S., GRENHA, A., CARRIÓN-RECIO, D., SEIJO, B. \& REMUÑáN-LÓPEZ, C. 2012. Microencapsulated chitosan nanoparticles for pulmonary protein delivery: In vivo evaluation of insulin-loaded formulations. Journal of Controlled Release, 157, 383-390.

AL-QADI, S., GRENHA, A. \& REMUÑÁN-LÓPEZ, C. 2011. Microspheres loaded with polysaccharide nanoparticles for pulmonary delivery: Preparation, structure and surface analysis. Carbohydrate Polymers, 86, 25-34.

ANWUNOBI, A. \& EMEJE, M. 2011. Recent applications of natural polymers in nanodrug delivery. Journal of Nanomedicine and Nanotechnology, S4, 2-7.

ARMSTEAD, A. \& LI, B. 2011. Nanomedicine as an emerging approach against intracellular pathogens. International Journal of Nanomedicine, 6, 3281-3293.

ATTAMA, A. 2011. SLN, NLC, LDC: State of the art in drug and active delivery. Recent Patents on Drug Delivery \& Formulation, 5, 178-187.

AZARMI, S., ROA, W. H. \& LÖBENBERG, R. 2008. Targeted delivery of nanoparticles for the treatment of lung diseases. Advanced Drug Delivery Reviews, 60, 863-875.

BARROW, W. 2004. Microsphere technology for chemotherapy of mycobacterial infections. Current Pharmaceutical Design, 10, 3275-3284.

BENEKE, C., VILJOEN, A. \& HAMMAN, J. 2009. Polymeric plant-derived excipients in drug delivery. Molecules, 14, 2602-2620.

BLASI, P., SCHOUBBEN, A., GIOVAGNOLI, S., ROSSI, C. \& RICCI, M. 2009. Fighting tuberculosis: old drugs, new formulations. Expert Opinion on Drug Delivery, 6, 977-993.

BORGES, O., CORDEIRO-DA-SILVA, A., ROMEIJN, S. G., AMIDI, M., DE SOUSA, A., BORCHARD, G. \& JUNGINGER, H. E. 2006. Uptake studies in rat Peyer's patches, cytotoxicity and release studies of alginate coated chitosan nanoparticles for mucosal vaccination. Journal of Controlled Release, 114, 348-58.

BRAZ, L., DIONÍSIO, M. \& GRENHA, A. 2011. Chitosan-based nanocarriers: effective vehicles for mucosal protein delivery. In: DAVIS, S. (ed.) Chitosan manufacture, properties and usage. New York: Nova Science Publishers.

CAI, Z., WANG, Y., ZHU, L.-J. \& LIU, Z.-Q. 2010. Nanocarriers: A general strategy for enhancement of oral bioavailability of poorly absorbed or pre-systemically metabolized drugs. Current Drug Metabolism, 11, 197-207. 
CAVALLI, R., BARGONI, A., PODIO, V., MUNTONI, E., ZARA, G. P. \& GASCO, M. R. 2003. Duodenal administration of solid lipid nanoparticles loaded with different percentages of tobramycin. Journal of Pharmaceutical Sciences, 92, 1085-1094.

CHIELLINI, F., PIRAS, A. M., ERRICO, C. \& CHIELLINI, E. 2008. Micro/nanostructured polymeric systems for biomedical and pharmaceutical applications. Nanomedicine, 3, 367-393.

D'AYALA, G. G., MALINCONICO, M. \& LAURIENZO, P. 2008. Marine derived polysaccharides for biomedical applications: chemical modification approaches. Molecules, 13, 2069-2106.

DEVI, N. \& MAJI, T. 2009. Preparation and evaluation of gelatin/sodium carboxymethyl cellulose polyelectrolyte complex microparticles for controlled delivery of isoniazid. AAPS PharmSciTech, 10, 1412-1419.

DOHERTY, T. \& ANDERSEN, P. 2005. Vaccines for tuberculosis: Novel concepts and recent progress. Clinical Microbiology Reviews, 18, 687-702.

DU TOIT, L., PILLAY, V. \& DANCKWERTS, M. 2006. Tuberculosis chemotherapy: current drug delivery approaches. Respiratory Research, 7, 118-135.

FLORENCE, A. 1997. The oral absorption of micro- and nanoparticulates: neither exceptional nor unusual. Pharmaceutical Research, 14, 259-266.

FONTE, P., ANDRADE, F., ARAÚJO, F., ANDRADE, C., NEVES, J. \& SARMENTO, B. 2012. Chitosancoated solid lipid nanoparticles for insulin delivery. Methods in Enzymology, 508, 295314.

GEISER, M. 2010. Update on macrophage clearance of inhaled micro- and nanoparticles. Journal of Aerosol Medicine and Pulmonary Drug Delivery, 23, 207-217.

GEORGE, M. \& ABRAHAM, T. E. 2006. Polyionic hydrocolloids for the intestinal delivery of protein drugs: Alginate and chitosan - a review. Journal of Controlled Release, 114, 114.

GRABOVAC, V., GUGGI, D. \& BERNKOP-SCHNURCH, A. 2005. Comparison of the mucoadhesive properties of various polymers. Advanced Drug Delivery Reviews, 2005, 1713-1723.

GRENHA, A., REMUÑ́́N-LÓPEZ, C., CARVALHO, E. L. S. \& SEIJO, B. 2008. Microspheres containing lipid/chitosan nanoparticles complexes for pulmonary delivery of therapeutic proteins. European Journal of Pharmaceutics and Biopharmaceutics, 69, 83-93.

GRENHA, A., SEIJO, B. \& REMUÑÁN-LÓPEZ, C. 2005. Microencapsulated chitosan nanoparticles for lung protein delivery. European Journal of Pharmaceutical Sciences, 25, 427-437.

HANS, M. \& LOWMAN, A. 2002. Biodegradable nanoparticles for drug delivery and targeting. Current Opinion in Solid State and Materials Science, 6, 319-327.

HIROTA, K., TOMODA, K., INAGAWA, H., KOHCHI, C., SOMA, G.-I., MAKINO, K. \& TERADA, H. 2008. Stimulation of phagocytic activity of alveolar macrophages toward artificial microspheres by infection with mycobacteria. Pharmaceutical Research, 25, 14201430.

HUNTER, R. L. 2011. On the pathogenesis of post primary tuberculosis: The role of bronchial obstruction in the pathogenesis of cavities. Tuberculosis, 91, Supplement 1, S6-S10.

HWANG, S. M., KIM, D. D., CHUNG, S. J. \& SHIM, C. K. 2008. Delivery of ofloxacin to the lung and alveolar macrophages via hyaluronan microspheres for the treatment of tuberculosis. Journal of Controlled Release, 129, 100-106.

LEHR, C.-M., BOUWSTRA, J. A., SCHACHT, E. H. \& JUNGINGER, H. E. 1992. In vitro evaluation of mucoadhesive properties of chitosan and some other natural polymers. International Journal of Pharmaceutics, 78, 43-48.

LEWIS, C. \& MCGEE, J. D. 1992. The macrophage, Oxford, IRL Press.

LIU, Z., JIAO, Y., WANG, Y., ZHOU, C. \& ZHANG, Z. 2008. Polysaccharides-based nanoparticles as drug delivery systems. Advanced Drug Delivery Reviews, 60, 1650-1662.

LU, E., FRANZBLAU, S., ONYUKSEL, H. \& POPESCU, C. 2009. Preparation of aminoglycosideloaded chitosan nanoparticles using dextran sulphate as a counterion. Journal of Microencapsulation, 26, 346-354. 
MALAFAYA, P., SILVA, G. \& REIS, R. 2007. Natural-origin polymers as carriers and scaffolds for biomolecules and cell delivery in tissue engineering application. Advanced Drug Delivery Reviews, 59, 207-233.

MARTINS, S., SARMENTO, B., FERREIRA, D. \& SOUTO, E. 2007. Lipid-based colloidal carriers for peptide and protein delivery - liposomes versus lipid nanoparticles. International Journal of Nanomedicine, 2, 595-607.

MISRA, A., HICKEY, A. J., ROSSI, C., BORCHARD, G., TERADA, H., MAKINO, K., FOURIE, P. B. \& COLOMBO, P. 2011. Inhaled drug therapy for treatment of tuberculosis. Tuberculosis, 91, 71-81.

MITCHISON, D. A. \& FOURIE, P. B. 2010. The near future: Improving the activity of rifamycins and pyrazinamide. Tuberculosis, 90, 177-181.

MIZOE, T., OZEKI, T. \& OKADA, H. 2008. Application of a four-fluid nozzle spray drier to prepare inhalable rifampicin-containing mannitol microspheres. AAPS PharmSciTech, 9, 755761.

MIZRAHY, S. \& PEER, D. 2012. Polysaccharides as building blocks for nanotherapeutics. The Chemistry Society Reviews, 41, 2623-2640.

MOSSER, D. 2003. The many faces of macrophage activation. Journal of Leukocyte Biology, 73, 209-212.

MURATA, Y., JINNO, D., LIU, D., ISOBE, T., KOFUJI, K. \& KAWASHIMA, S. 2007. The drug release profile from calcium-induced alginate gel beads coated with an alginate hydrolysate. Molecules, 12, 2559-2566.

NIMJE, N., AGARWAL, A., SARAOGI, G. K., LARIYA, N., RAI, G., AGRAWAL, H. \& AGRAWAL, G. P. 2009. Mannosylated nanoparticulate carriers of rifabutin for alveolar targeting. Journal of Drug Targeting, 17, 777-787.

PANDEY, R. \& AHMAD, Z. 2011. Nanomedicine and experimental tuberculosis: facts, flaws, and future. Nanomedicine: Nanotechnology, Biology and Medicine, 7, 259-272.

PANDEY, R. \& KHULLER, G. K. 2004. Chemotherapeutic potential of alginate-chitosan microspheres as anti-tubercular drug carriers. Journal of Antimicrobial Chemotherapy, 53, 635-640.

PANDEY, R. \& KHULLER, G. K. 2005a. Antitubercular inhaled therapy: opportunities, progress and challenges. Journal of Antimicrobial Chemotherapy, 55, 430-435.

PANDEY, R. \& KHULLER, G. K. 2005b. Solid lipid particle-based inhalable sustained drug delivery system against experimental tuberculosis. Tuberculosis, 85, 227-234.

PANDEY, R., SHARMA, S. \& KHULLER, G. K. 2005. Oral solid lipid nanoparticle-based antitubercular chemotherapy. Tuberculosis, 85, 415-420.

PINHEIRO, M., LÚCIO, M., LIMA, J. \& REIS, S. 2011. Liposomes as drug delivery systems for the treatment of TB. Nanomedicine, 6, 1413-1428

PINTO REIS, C., NEUFELD, R. J., RIBEIRO, A. J. \& VEIGA, F. 2006. Nanoencapsulation I. Methods for preparation of drug-loaded polymeric nanoparticles. Nanomedicine: Nanotechnology, Biology and Medicine, 2, 8-21.

RANJITA, S., LOAYE, A. \& KHALIL, M. 2011. Present status of nanoparticle research for treatment of tuberculosis. Journal of Pharmacy and Pharmaceutical Sciences, 14, 100116.

RUSSELL, D. 2007. Who puts the tubercle in tuberculosis? Nature Reviews of Microbiology, 5, 39-47.

SARAOGI, G. K., GUPTA, P., GUPTA, U. D., JAIN, N. K. \& AGRAWAL, G. P. 2010. Gelatin nanocarriers as potential vectors for effective management of tuberculosis. International Journal of Pharmaceutics, 385, 143-149.

SARAOGI, G. K., SHARMA, B., JOSHI, B., GUPTA, P., GUPTA, U. D., JAIN, N. K. \& AGRAWAL, G. P. 2011. Mannosylated gelatin nanoparticles bearing isoniazid for effective management of tuberculosis. Journal of Drug Targeting, 19, 219-227. 
SMOLA, M., VANDAMME, T. \& SOKOLOWSKI, A. 2008. Nanocarriers as pulmonary drug delivery systems to treat and to diagnose respiratory and non respiratory diseases. International Journal of Nanomedicine, 3, 1-19.

SOSNIK, A., CARCABOSO, Á. M., GLISONI, R. J., MORETTON, M. A. \& CHIAPPETTA, D. A. 2010. New old challenges in tuberculosis: Potentially effective nanotechnologies in drug delivery. Advanced Drug Delivery Reviews, 62, 547-559.

SUDHAKAR, Y., KUOTSU, K. \& BANDYOPADHYAY, A. 2006. Buccal bioadhesive drug delivery A promising option for orally less efficient drugs. Journal of Controlled Release, 114, 15-40.

TAYLOR, P., MARTINEZ-POMARES, L., STACEY, M., LIN, H.-H., BROWN, G. \& GORDON, S. 2005. Macrophage receptors and immune recognition. Annual Reviews in Immunology, 23, 901-944.

YADAV, A. B., SINGH, A. K., VERMA, R. K., MOHAN, M., AGRAWAL, A. K. \& MISRA, A. 2011. The devil's advocacy: When and why inhaled therapies for tuberculosis may not work. Tuberculosis, 91, 65-66.

YEBOAH, K. G. \& D'SOUZA, M. J. 2009. Evaluation of albumin microspheres as oral delivery system for Mycobacterium tuberculosis vaccines. Journal of Microencapsulation, 26, 166-179.

ZARA, G. P., BARGONI, A., CAVALLI, R., FUNDARÒ, A., VIGHETTO, D. \& GASCO, M. R. 2002. Pharmacokinetics and tissue distribution of idarubicin-loaded solid lipid nanoparticles after duodenal administration to rats. Journal of Pharmaceutical Sciences, 91, 13241333.

\section{Figure legends}

Figure 1. Chemical structures of natural materials used in the production of multiparticulate carriers proposed for tuberculosis therapy.

Figure 2. Tissue levels of alginate-encapsulated isoniazid, rifampicin and pyrazinamide (in combination) when administered orally to guinea pigs. Values are means \pm S.D. of 7-8 animals. Reproduced from Ain et al. (2003) with permission.

Figure 3. The profile of anti-tuberculous drugs in plasma following the single oral administration of ATD-loaded alginate-chitosan microspheres and free drugs (in combination) to guinea pigs. (a) Plasma rifampicin; (b) plasma isoniazid; and (c) plasma pyrazinamide. Values are means \pm S.D. of eight animals for alginate-chitosan microspheres and six animals for free drugs. Reproduced from Pandey and Khuller (2004) with permission. 
Table 1. Advantages and limitations of natural polymers for the production of drug delivery carriers.

\begin{tabular}{ll}
\hline Advantages & Limitations \\
\hline Flexibility & Inter-batch variability \\
Low cost & Limited availability (if widely used) \\
Ease of extraction & Complex and varied composition \\
Hydrophilicity & Difficult to process \\
Biocompatibility, biodegradability & Low mechanic properties \\
\hline
\end{tabular}


Table 2. Description of studies performed with natural micro- and nanocarriers in the ambit of anti-tubercular drug delivery.

\begin{tabular}{|c|c|c|c|c|c|}
\hline Materials & $\begin{array}{l}\text { Associated } \\
\text { molecules }\end{array}$ & $\begin{array}{l}\text { Administration } \\
\text { route }\end{array}$ & $\begin{array}{l}\text { Drug delivery } \\
\text { system }\end{array}$ & Major findings & Ref. \\
\hline $\begin{array}{l}\text { Gelatin } \\
\text { Carboxymethyl } \\
\text { cellulose }\end{array}$ & Isoniazid & Not applicable & Microparticles & $\begin{array}{l}\text { Glutaraldehyde acted as cross-linker, modulating drug release }(17.5 \\
\text { mmol glutaraldehyde/g of polymer provided } 70 \% \text { release in } 48 \mathrm{~h})\end{array}$ & $\begin{array}{l}\text { (Devi and Maji, } \\
\text { 2009) }\end{array}$ \\
\hline Alginate & $\begin{array}{l}\text { Isoniazid, } \\
\text { rifampicin, } \\
\text { pyrazinamide }\end{array}$ & Oral & Microparticles & $\begin{array}{l}\text { Encapsulation provided plasma drug levels for } 3 \text { to } 5 \text { days, while free } \\
\text { drugs were eliminated within } 24 \mathrm{~h} \text {, after single dose administration to } \\
\text { guinea pigs. Encapsulated drugs were detected in tissue up to } 9 \text { days, } \\
\text { while free drugs only for } 48 \mathrm{~h}\end{array}$ & (Ain et al., 2003) \\
\hline $\begin{array}{l}\text { Alginate } \\
\text { Chitosan }\end{array}$ & $\begin{array}{l}\text { Isoniazid, } \\
\text { rifampicin, } \\
\text { pyrazinamide }\end{array}$ & Oral & Microparticles & $\begin{array}{l}\text { Encapsulated drugs provided } 15 \text {-fold and } 13 \text {-fold increase in drug half- } \\
\text { life and mean residence time, respectively }\end{array}$ & $\begin{array}{l}\text { Pandey and } \\
\text { Khuller, 2004) }\end{array}$ \\
\hline Hyaluronic acid & Ofloxacin & Intratracheal & Microparticles & $\begin{array}{l}\text { Microencapsulated ofloxacin resulted in less than } 50 \% \text { bioavailability as } \\
\text { compared with control intravenous and oral administration of drug } \\
\text { solution to rats. Lung drug concentration was } 10 \text {-times higher after direct } \\
\text { lung delivery }\end{array}$ & $\begin{array}{l}\text { (Hwang et al., } \\
\text { 2008) }\end{array}$ \\
\hline Mannitol & Rifampicin & Intratracheal & Microparticles & $\begin{array}{l}\text { Drug elimination is very rapid, with only } 4 \% \text { of drug remaining in the } \\
\text { lung } 1 \mathrm{~h} \text { after administration }\end{array}$ & $\begin{array}{l}\text { (Mizoe et al., } \\
\text { 2008) }\end{array}$ \\
\hline $\begin{array}{l}\text { Alginate } \\
\text { Chitosan }\end{array}$ & $\begin{array}{l}\text { Isoniazid, } \\
\text { rifampicin, } \\
\text { pyrazinamide }\end{array}$ & Pulmonary & Nanoparticles & $\begin{array}{l}\text { Nebulised nanoparticles display a respirable fraction of } 80 \% \text {. Drug levels } \\
\text { detected in plasma up to } 14 \text { days after nanoparticle administration, while } \\
\text { only } 24 \mathrm{~h} \text { after free drug administration. Encapsulation provided } \\
\text { enhanced tissue bioavailability }\end{array}$ & $\begin{array}{l}\text { (Ahmad et al., } \\
\text { 2005b) }\end{array}$ \\
\hline $\begin{array}{l}\text { Alginate } \\
\text { Chitosan }\end{array}$ & $\begin{array}{l}\text { Isoniazid, } \\
\text { rifampicin, } \\
\text { pyrazinamide, } \\
\text { etambutol }\end{array}$ & Oral & Nanoparticles & $\begin{array}{l}\text { Administration of nanoencapsulated drugs provided plasma drug levels } \\
\text { for } 7-13 \text { days and tissue levels for } 15 \text { days. Free drugs were eliminated } \\
\text { within } 24 \mathrm{~h}\end{array}$ & $\begin{array}{l}\text { (Ahmad et al., } \\
\text { 2006c) }\end{array}$ \\
\hline Stearic acid & $\begin{array}{l}\text { Isoniazid, } \\
\text { rifampicin, } \\
\text { pyrazinamide }\end{array}$ & Oral & $\begin{array}{l}\text { Solid lipid } \\
\text { nanoparticles }\end{array}$ & $\begin{array}{l}\text { Therapeutic drug levels detected in plasma for } 8 \text { days and in tissue for } 10 \\
\text { days }\end{array}$ & $\begin{array}{l}\text { (Pandey et al., } \\
\text { 2005) }\end{array}$ \\
\hline Stearic acid & $\begin{array}{l}\text { Isoniazid, } \\
\text { rifampicin, } \\
\text { pyrazinamide }\end{array}$ & Pulmonary & Solid lipid particles & $\begin{array}{l}\text { Therapeutic drug levels detected in plasma for } 5 \text { days and in tissue for } 7 \\
\text { days }\end{array}$ & $\begin{array}{l}\text { (Pandey and } \\
\text { Khuller, 2005b) }\end{array}$ \\
\hline $\begin{array}{l}\text { Stearic acid } \\
\text { Mannose }\end{array}$ & Rifabutin & Intravenous & $\begin{array}{l}\text { Solid lipid } \\
\text { nanoparticles }\end{array}$ & $\begin{array}{l}\text { Mannosylation increases macrophage particle uptake by } 6 \text {-fold and } \\
\text { provides prolonged drug plasma levels ( } 96 \mathrm{~h} \text { as compared to } 72 \mathrm{~h} \text { of non- } \\
\text { mannosylated nanoparticles and } 48 \mathrm{~h} \text { for free drug) }\end{array}$ & $\begin{array}{l}\text { (Nimje et al., } \\
\text { 2009) }\end{array}$ \\
\hline
\end{tabular}


Table 3. Description of in vivo studies performed with natural micro- and nanocarriers in animal models of tuberculosis.

\begin{tabular}{|c|c|c|c|c|c|}
\hline Materials & $\begin{array}{l}\text { Associated } \\
\text { molecules }\end{array}$ & $\begin{array}{l}\text { Drug delivery } \\
\text { system }\end{array}$ & $\begin{array}{l}\text { Animal/Route of } \\
\text { administration }\end{array}$ & Major findings & Ref. \\
\hline Alginate & $\begin{array}{l}\text { Isoniazid, } \\
\text { rifampicin, } \\
\text { pyrazinamide }\end{array}$ & Microparticles & $\begin{array}{l}\text { Guinea pig } \\
\text { Oral }\end{array}$ & $\begin{array}{l}\text { Once-a-week administration of encapsulated drugs for } 8 \text { weeks eliminated } \\
\text { bacilli from lungs and spleen. Once-a-day administration of free drugs for } \\
\text { the same period achieved the same result. }\end{array}$ & (Ain et al., 2003) \\
\hline $\begin{array}{l}\text { Alginate } \\
\text { Chitosan }\end{array}$ & $\begin{array}{l}\text { Isoniazid, } \\
\text { rifampicin, } \\
\text { pyrazinamide }\end{array}$ & Microparticles & $\begin{array}{l}\text { Guinea pigs } \\
\text { Oral }\end{array}$ & $\begin{array}{l}\text { Five doses of microencapsulated drugs at therapeutic concentration or } 7 \\
\text { doses at half-therapeutic concentration, administered with } 10 \text {-day interval } \\
\text { eliminated bacilli. Same effect observed for } 46 \text { daily doses of free drugs. }\end{array}$ & $\begin{array}{l}\text { (Pandey and } \\
\text { Khuller, 2004) }\end{array}$ \\
\hline $\begin{array}{l}\text { Alginate } \\
\text { Chitosan }\end{array}$ & $\begin{array}{l}\text { Isoniazid, } \\
\text { rifampicin, } \\
\text { pyrazinamide }\end{array}$ & Nanoparticles & $\begin{array}{l}\text { Guinea pigs } \\
\text { Pulmonary }\end{array}$ & $\begin{array}{l}\text { Bacilli elimination was achieved with } 3 \text { doses of nebulised nanoparticles in a } \\
\text { total of } 45 \text { days. Similar effect obtained upon } 45 \text { daily doses of free oral } \\
\text { drugs }\end{array}$ & $\begin{array}{l}\text { (Ahmad et al., } \\
2005 b)\end{array}$ \\
\hline $\begin{array}{l}\text { Alginate } \\
\text { Chitosan }\end{array}$ & $\begin{array}{l}\text { Isoniazid, } \\
\text { rifampicin, } \\
\text { pyrazinamide, } \\
\text { etambutol }\end{array}$ & Nanoparticles & $\begin{array}{l}\text { Mice } \\
\text { Oral }\end{array}$ & $\begin{array}{l}\text { Nanoencapsulated drugs administered fortnightly permitted bacterial } \\
\text { elimination after } 3 \text { doses, while free drugs needed } 45 \text { daily doses }\end{array}$ & $\begin{array}{l}\text { (Ahmad et al., } \\
\text { 2006a) }\end{array}$ \\
\hline $\begin{array}{l}\text { Alginate } \\
\text { Chitosan }\end{array}$ & $\begin{array}{l}\text { Isoniazid, } \\
\text { rifampicin, } \\
\text { pyrazinamide, } \\
\text { etambutol, } \\
\text { econazole }\end{array}$ & Nanoparticles & $\begin{array}{l}\text { Mice } \\
\text { Oral }\end{array}$ & $\begin{array}{l}\text { Fortnight administration of any } 3 \text { of the nanoencapsulated drugs selected } \\
\text { from isoniazid, rifampicin, pyrazinamide and etambutol plus weekly } \\
\text { administration of nanoencapsulated econazole eliminated bacteria after } 30 \\
\text { days. }\end{array}$ & $\begin{array}{l}\text { (Ahmad et al., } \\
\text { 2007) }\end{array}$ \\
\hline $\begin{array}{l}\text { Chitosan } \\
\text { Dextran sulfate }\end{array}$ & Streptomycin & Nanoparticles & $\begin{array}{l}\text { Mice } \\
\text { Oral }\end{array}$ & $\begin{array}{l}\text { Daily administration of chitosan-coated streptomycin/dextran sulfate } \\
\text { complexes for } 3 \text { weeks decreases } 15 \% \text { bacterial levels; the same result } \\
\text { obtained for similar schedule of subcutaneous administration of free drug }\end{array}$ & (Lu et al., 2009) \\
\hline Gelatin & Rifampicin & Nanoparticles & $\begin{array}{l}\text { Mice } \\
\text { Intravenous }\end{array}$ & $\begin{array}{l}\text { Ten doses of encapsulated drug administered every } 3 \text { days reduced } 50 \% \\
\text { bacterial levels in lung and spleen }\end{array}$ & $\begin{array}{l}\text { (Saraogi et al., } \\
\text { 2010) }\end{array}$ \\
\hline $\begin{array}{l}\text { Gelatin } \\
\text { Mannose }\end{array}$ & Isoniazid & Nanoparticles & $\begin{array}{l}\text { Mice } \\
\text { Intravenous }\end{array}$ & $\begin{array}{l}\text { Drug-loaded mannosylated-nanoparticles achieved } 3 \text {-fold higher reduction } \\
\text { of bacterial levels as compared to free drug }\end{array}$ & $\begin{array}{l}\text { (Saraogi et al., } \\
\text { 2011) }\end{array}$ \\
\hline Stearic acid & $\begin{array}{l}\text { Isoniazid, } \\
\text { rifampicin, } \\
\text { pyrazinamide }\end{array}$ & $\begin{array}{l}\text { Solid lipid } \\
\text { nanoparticles }\end{array}$ & $\begin{array}{l}\text { Mice } \\
\text { Oral }\end{array}$ & $\begin{array}{l}\text { Five oral doses administered each } 10 \text { days resulted in bacterial elimination. } \\
\text { Similar results observed upon } 46 \text { daily doses of free drugs }\end{array}$ & $\begin{array}{l}\text { (Pandey et al., } \\
\text { 2005) }\end{array}$ \\
\hline Stearic acid & $\begin{array}{l}\text { Isoniazid, } \\
\text { rifampicin, } \\
\text { pyrazinamide }\end{array}$ & $\begin{array}{l}\text { Solid lipid } \\
\text { nanoparticles }\end{array}$ & $\begin{array}{l}\text { Guinea pigs } \\
\text { Pulmonary }\end{array}$ & Seven weekly doses of encapsulated drug provided bacilli elimination & $\begin{array}{l}\text { (Pandey and } \\
\text { Khuller, 2005b) }\end{array}$ \\
\hline
\end{tabular}

URL: http://mc.manuscriptcentral.com/tmnc Email: microencapsulation@hotmail.co.uk 
1

2

3

4

5

6

7

8

9

10

11

12

13

14

15

16

17

18

19

20

21

22

23

24

25

26

27

28

29

30

31

32

33

34

35

36

37

38

39

40

41

42

43

44

45

46

47

48

49

50

51

52

53

54

55

56

57

58

59

60

Table 4. Chemotherapeutic efficacy of aerosolised alginate nanoparticle encapsulating antitubercular drugs against experimental tuberculosis in guinea pigs. Reproduced from Ahmad et al. (2005b) with permission.

\begin{tabular}{lll}
\hline Group & \multicolumn{1}{l}{$\log 10 \mathrm{CFUs}^{\mathrm{a}}$} \\
\cline { 2 - 3 } & $\begin{array}{l}\text { Lung (right caudal } \\
\text { lobe) }\end{array}$ & $\begin{array}{l}\text { Spleen } \\
\text { (whole organ) }\end{array}$ \\
\hline Untreated controls & $5.8 \pm 0.1$ & $5.9 \pm 0.1$ \\
$\begin{array}{l}\text { Empty alginate nanoparticles every 15 days, } \\
\text { aerossol (3 doses) }\end{array}$ & $5.8 \pm 0.3^{*}$ & $5.9 \pm 0.1$ \\
$\begin{array}{l}\text { Drug-loaded alginate nanoparticles every 15 } \\
\text { days, aerosol (3 doses) }\end{array}$ & $<1.0^{\mathrm{b}}$ & $<1.0^{\mathrm{b}}$ \\
\begin{tabular}{l} 
Free drugs daily, orally (45 doses) \\
\hline
\end{tabular} & $<1.0^{\mathrm{b}}$ & $<1.0^{\mathrm{b}}$ \\
\hline
\end{tabular}

${ }^{a}$ Results are based on visible growth of Mycobacterium tuberculosis on Middlebrook 7H10 agar on day 21 post inoculation. Results are mean \pm S.D $(N=5-6) ;{ }^{\mathrm{b}}$ Value $<1.0$ indicates no detectable CFUs following the inoculation of $50 \mu \mathrm{L}$ of neat and 1:10 diluted tissue homogenates; ${ }^{*} P>0.05$ according to ANOVA; CFUs: colony forming units. 

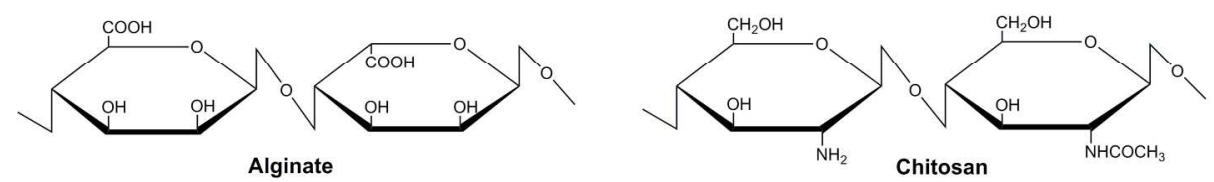

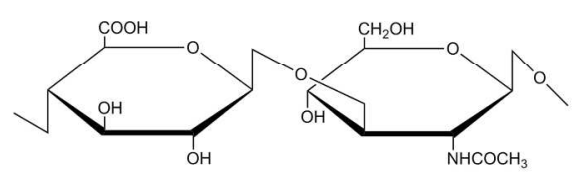

Hyaluronic acid

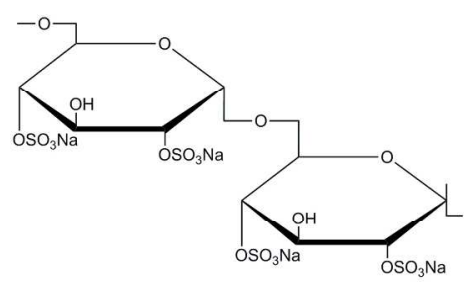

Dextran sulfate

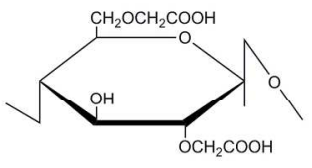

Carboxymethyl cellulose<smiles>OC[C@@H](O)[C@@H](O)[C@H](O)[C@H](O)CO</smiles>

Mannitol
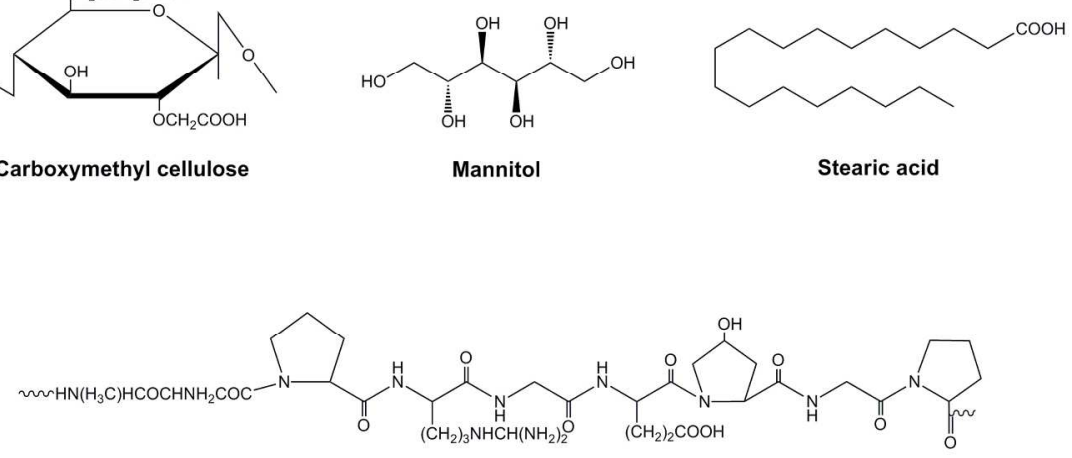

Gelatin

Figure 1. Chemical structures of natural materials used in the production of multiparticulate carriers proposed for tuberculosis therapy. 

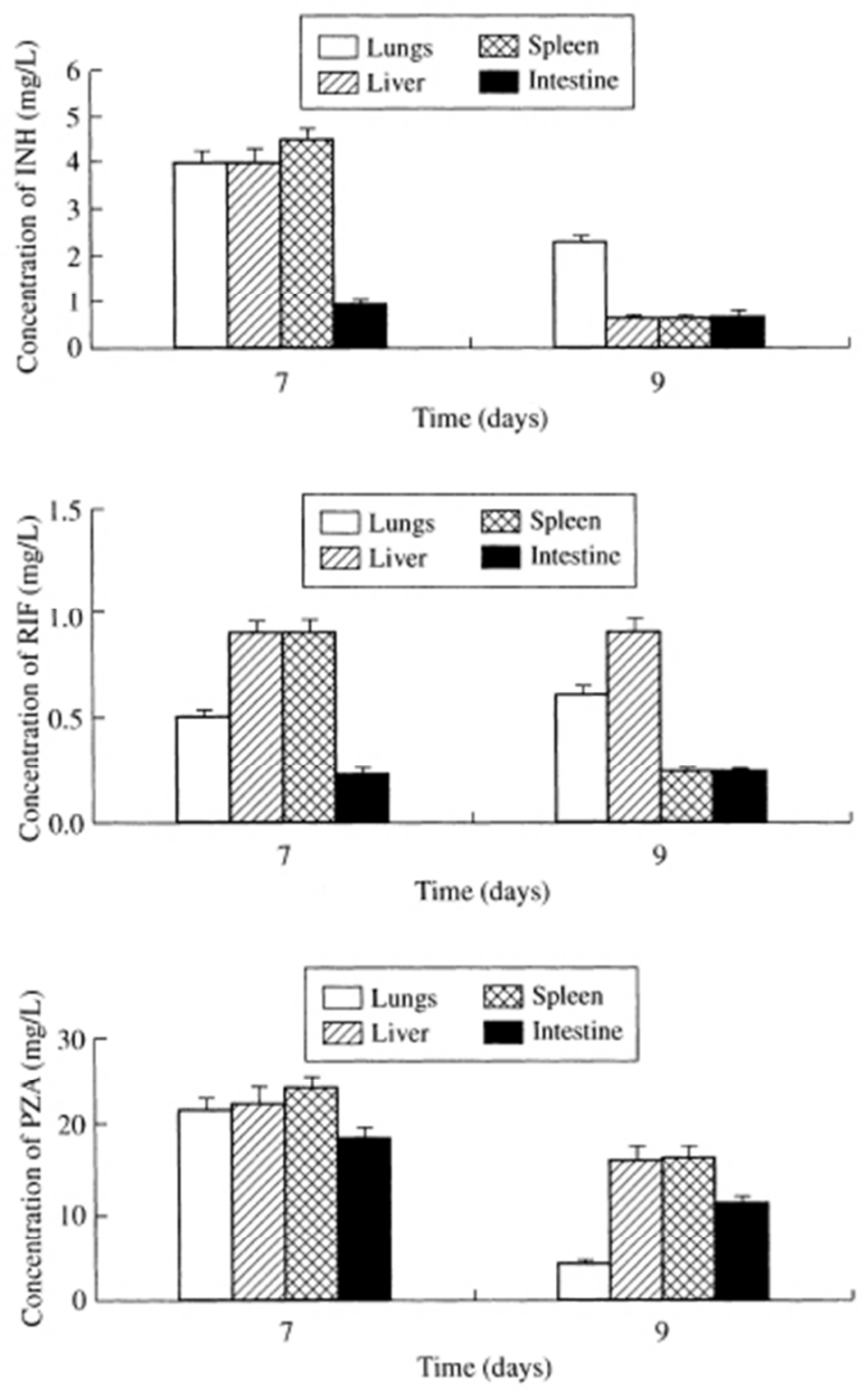

Figure 2. Tissue levels of alginate-encapsulated isoniazid, rifampicin and pyrazinamide (in combination) when administered orally to guinea pigs. Values are means \pm S.D. of 7-8 animals. Reproduced from Ain et al. (2003) with permission. $133 \times 217 \mathrm{~mm}(72 \times 72 \mathrm{DPI})$ 
(a)

Figure 3. The profile of anti-tuberculous drugs in plasma following the single oral administration of ATDloaded alginate-chitosan microspheres and free drugs (in combination) to guinea pigs. (a) Plasma rifampicin; (b) plasma isoniazid; and (c) plasma pyrazinamide. Values are means \pm S.D. of eight animals for alginate-chitosan microspheres and six animals for free drugs. Reproduced from Pandey and Khuller (2004) with permission. $143 \times 218 \mathrm{~mm}(72 \times 72 \mathrm{DPI})$ 